\title{
Work It: Looking at Labour and Compensation in Canadian Non-Commercial Scholarly Journals
}

Jessica Lange, McGill University

Sarah Severson, University of Alberta

DOI

https://doi.org/10.18357/kula.151

\begin{abstract}
The goal of this paper is to document how labour is divided and compensated (both monetarily and non-monetarily) in Canadian non-commercial scholarly journals. This study informs future research on sustainability in non-commercial academic publishing. As labour is essential for the continued success of these journals, understanding the extent (i.e., how many positions, how many hours per position), scope (i.e., which tasks are undertaken and who is responsible for them), and cost (monetary or non-monetary) of this labour will be critical in ensuring the sustainability of non-commercial academic journals in Canada. To investigate current practices, the authors distributed a survey to 484 Canadian journals meeting the above inclusion criteria. The survey was composed of two sections: how labour is divided at a journal (i.e., how many positions are there, what are the responsibilities of these positions, and how many work hours per week are dedicated to these positions) and compensation (i.e., does the journal provide monetary or non-monetary compensation to members of its editorial team, which positions receive compensation, and what is the source of these funds). The authors received 119 responses, for a 25 percent response rate. Among the main findings are that the majority of respondents compensate at least one journal position and that the source of these funds comes primarily from sponsoring organizations (i.e., affiliated institutional/university departments and scholarly associations). Additional findings include that the top three most commonly compensated positions are copyeditor, editorial assistant, and managing editor. Compensated positions such as translator, graphic designer, and copyeditor are often contracted out. Task distribution amongst editorial team members varies; however, editors-in-chief and managing editors are responsible for the greatest variety of tasks. Editorial assistants and managing editors tend to work more hours than other positions. Additionally, journal production was related to editorial team size, with larger teams producing more volumes on average than smaller ones. Recurring themes in free-text comments were large workloads, lack of compensation, and lack of recognition. This paper provides empirical evidence of the extent and variation of labour and compensation in Canadian non-commercial scholarly publishing. It provides data on current non-commercial
\end{abstract}


journal practices which will be of interest to library publishers, journal editors, and other stakeholders in Canadian scholarly publishing.

Keywords: Canadian scholarly publishing; labour; editorial teams; non-commercial journals

\section{Introduction}

The goal of this paper is to document how labour is divided and compensated (both monetarily and non-monetarily) in Canadian non-commercial scholarly journals. As labour is essential for the continued success of these journals, understanding the extent (i.e., how many positions, how many hours per position), scope (i.e., which tasks are undertaken and who is responsible for them), and cost (monetary or non-monetary) of this labour will be critical in ensuring the sustainability of non-commercial academic journals in Canada.

Due to recent growth in open access and electronic journal formats, the scholarly publishing landscape has changed dramatically. The open access movement emerged partly in response to rising prices imposed by commercial journal publishers (Suber 2012). Proponents of open access believe that non-commercial publishers are an important alternative to commercial companies, integral for creating a scholar-led publishing ecosystem (Maryl et al. 2020; Schlosser 2019). However, non-commercial journals are often smaller than commercial journals and led by a dedicated few individuals, frequently unpaid, who take on the labour of running them. This reliance on the volunteer labour of a small pool of people threatens the sustainability of noncommercial scholarly publishing; yet, little data has been gathered on the extent of the labour required to operate a scholarly journal, non-commercial or otherwise. In their review of independent journals, ${ }^{1}$ Björk, Shen, and Laakso note that although journals rely on labour, minimal attention is typically given to "the tasks involved in coordinating and motivating the network of editors, editorial board members, reviewers, submitting editors etc. which are an essential part of running a journal" $(2016,2)$.

Research that unpacks the extent of labour behind non-commercial scholarly journals comes at a critical time in academia. Working on a scholarly journal editorial team is generally counted in tenure and promotion as service to the academic community and is expected of tenured and tenure-track professors as a component of their salaried positions (Fyfe and Gielas 2020; Schimanski and Alperin 2018). But there has been a noted decline in the number of tenure-track positions in Canada and the United States over the past several decades (Foster and Birdsell Bauer 2018; Magness 2016). With declining tenure-track positions and more adjunct faculty, there may be fewer scholars who can afford to spend volunteer hours on a scholarly publication. Compounding this dilemma, many tenured and tenure-track faculty believe that service is not properly recognized by their institution (see Mamiseishvili, Miller, and Lee 2016). Based on these factors, it follows that increasingly few scholars will have the time, resources, and willingness to undertake editorial work.

\footnotetext{
${ }^{1}$ Björk, Shen, and Laakso (2016) define independent journals as being associated neither with a commercial publisher nor with a society/association. We take a broader approach in our study as we included journals associated with a society/association. Even though their scope is narrower, Björk, Shen, and Laakso (2016) still provide relevant information on how journals without commercial backing operate.
} 
Therefore, to sustain an ecosystem of non-commercial scholarly journals in Canada, we need a better understanding of the demands on the members of a journal team - in terms of time investment and responsibilities - and the compensation they receive. While we recognize that similar labour issues may apply to commercial journals, this study focuses on non-commercial journals because they serve as a bulwark against the encroaching for-profit publishing world. We distributed a survey to 484 Canadian non-commercial scholarly journals to understand the size, extent, and compensation of labour in these journals. This journal corpus was developed from sources including Ulrich's Periodicals Directory, Érudit, the Canadian Association of Learned Journals (CALJ), the Social Sciences and Humanities Research Council of Canada (SSHRC) Aid to Scholarly Journal (ASJ) grant award winners, and the Canadian Research Knowledge Network (CRKN) list of open access journals.

\section{Background}

\section{Canadian Publishing Landscape}

Canadian scholarly journals continue to adapt to a changing publishing landscape, notably through the recent rise of open access. Non-open access journals face several questions: do they "open" their journal? If so, do they charge author fees to make up for lost subscription revenue? Are author fees standard in their discipline? Which economic model should they pursue? These questions became even more pressing in 2018, when the SSHRC ASJ program mandated that ASJ recipients make their journal content open within twelve months of publication. The SSHRC ASJ program has existed in various iterations since the 1940s and has been an important stabilizing force for many Canadian journals, providing up to $\$ 30,000$ a year for three years (renewable) to eligible journals (Government of Canada 2018). According to a CALJ letter to the minister in charge of the ASJ program, the 2018 change was perceived to negatively affect revenue models and required journals to consider new scenarios to meet changing industry demands (Clavette 2018). In response to this change made by ASJ, a report from the Canadian Journal of Political Science outlined means of adaptation that the journal might take: moving to a gold open access model, forgoing future SSHRC funding and maintaining its current publishing model, or moving to a twelve-month embargo for journal content (Papillon et al. 2019). The journal chose the latter option, and the report illustrates the various scenarios and adaptations Canadian journals must face in the current publishing climate.

Efforts have recently been made to assist Canadian journals as they navigate this landscape. Coalition Publica - a partnership of the Public Knowledge Project (the group behind the Open Journal Systems software) and Erudit (the Canadian non-profit hosting platform) - demonstrates an emerging model. Operating in a cooperative format, Canadian libraries provide funds to Coalition Publica, which are then redistributed to Canadian journals meeting their inclusion criteria. Journals may then use these funds to offset some of their costs while simultaneously taking advantage of the publishing services and the dissemination platform of Érudit.

Canadian libraries also demonstrate a vested interest in the health of Canadian journals. This is exemplified in part by their commitment to Coalition Publica but also by the rise of library 
publishers. Over four hundred journals are currently supported by Canadian libraries in various capacities (e.g., hosting, indexing, etc.), and library support will continue to be an important component in a national strategy to provide sustainable, low-cost publishing options for journals (Canadian Association of Research Libraries 2017).

As labour is a significant component of scholarly publishing, libraries and other partners in scholarly communications who are invested in the sustainability of non-commercial scholarly journals should be aware of and concerned about current labour practices given some notable trends in academic burnout and productivity. Documenting and creating a shared understanding of the extent (i.e., how many positions, how many hours per position), scope (i.e., which tasks are undertaken and who is responsible for them), and cost (monetary or non-monetary) of labour is integral to fostering a robust, affordable scholarly publishing ecosystem in Canada.

\section{Literature Review}

Prior scholarship on editorial labour can be organized into four broad categories: best practice documentation, studies on editorial workloads, productivity and burnout, and sustainability.

\section{Best Practice Documentation}

Best practice documents, created and distributed by a variety of publishers, describe how to establish a journal's editorial board and common editorial practices. The documents may assist journals in defining positions and assigning tasks. For example, the commercial publisher Wiley's (n.d.) "Editorial Resources" page provides basic information on editorial board structure, the peer review process, and communicating with authors. In a similar vein, CALJ has a set of resources related to business models for scholarly journals (Canadian Association of Learned Journals n.d). PKP, in their "Student Journal Toolkit," also provides an overview of common editorial roles and responsibilities as well as sample position requirements (Public Knowledge Project n.d.). These types of documents are widely available, free, and may be consulted by both commercial and non-commercial journals.

While these documents are beneficial for understanding the general positions at a journal and a journal's work processes, they are light on details concerning how many positions a journal should have, how a journal should distribute its work among team members, what kinds of compensation should be provided (if any), and how many hours a team member should expect to contribute to a role. The lack of prescription can be beneficial because it permits journals to determine their own structures according to their own needs. But journals looking for specific guidance on labour distribution - the workload and time commitment for different positionswill not find such advice in these documents.

\section{Editorial Workloads: Work Hours and Size of Editorial Boards}

One of the first research studies to investigate editorial labour was Giménez-Toledo et al. (2009). In a survey of 132 Spanish scholarly journals, they asked respondents about editorial structure and task division on editorial boards. The authors wanted to compare their findings to established best practice literature on how to structure editorial boards. They found that many functions were carried out collectively and that editorial boards carry out most of a journal's work in 
collaboration with an executive editor. They also determined that the mode number of six editorial members "strikes the balance between the need for an operative structure and the ability to carry out a large part of the editorial work" (Giménez-Toledo et al. 2009, 293).

Similar to Giménez-Toledo et al. (2009), Edgar and Willinsky's (2010) survey of journals publishing on the open-source publishing software OJS found that the average number of editors at the journals in their survey was seven. This number aligned with SSHRC's finding that ASJeligible journals had between five and seven volunteers (SSHRC Evaluation Division 2020). These numbers contrast with the reported 3.5 editors at Elsevier's commercial journals (cited in Edgar and Willinsky 2010, 10). Like Giménez-Toledo et al. (2009), Edgar and Willinsky theorized that the greater number of editors permitted the journals in their sample to better distribute the workload $(2010,10)$. The distribution of workload is key to a journal's sustainability, as noted in Björk, Shen, and Laakso's (2016) brief case study of the "indie" journal Electronic Journal of Information Technology in Construction. Edgar and Willinksy (2010) also examined editorial task divisions, examining in particular who undertakes copyediting, layout, and proofreading at a journal. They found that journal editors were the primary position responsible in each of those processes and that editors worked on average seven hundred hours annually for their journals, with some respondents noting that they worked full time on the journal. Less than half of respondents received compensation in some capacity (Edgar and Willinsky 2010).

While the Edgar and Willinsky (2010) study was international in focus, the non-profit hosting platform Érudit undertook a survey and series of interviews to investigate the socio-economic situation of Canadian scholarly journals. The resulting report by Paquin (2016), "Shaping a Collective Future: An Investigation into Canadian Scholarly Journals' Socio-Economic Reality and an Outlook on the Partnership Model for Open Access," primarily focused on revenues and expenditures of Canadian scholarly journals. It did, however, include information related to labour and its related costs. According to the report, 45 percent of a journal's expenses went to salaries. The survey also asked journal respondents to estimate the financial value of the time and contributions volunteers made, which across the fifty-six respondents returned an average of $\$ 33,000$ per year. Paquin (2016) notes, however, that this estimate is not based on any distinct calculations by the journals and is likely highly subjective. Overall, while Érudit's study includes both commercial and non-commercial journals, it provides a basic picture of the extent of labour in Canadian scholarly publishing.

\section{Productivity and Burnout}

Baruch (2008) conducted a survey of over fifty editors of scholarly journals in the management and behavioural sciences. He found that the average number of hours worked per week by an editor was fifteen. Combining this statistic with editors' other working hours as tenured academics, Baruch writes that "it seems being a workaholic is an inherent requirement for this job" $(2008,685)$. Although there were many positive attributes associated with being an editor (e.g., a stronger collegial network, respect from colleagues, etc.), there were also many negative effects indicated by editors in their survey responses, the top among them "generating work related-stress" and "hindering research/development progress" (Baruch 2008, 685). Although not based on survey data, several other studies include anecdotal observations about the large amount of work involved in editorial positions (Fischer 2010; Donovan 2013; Zedeck 2008). 
Given the time commitment, it is not surprising that Hames writes that, in her experiences with Plant Journal, one of the key ingredients in keeping an editor happy is avoiding "work overload" (2001, 252). Sellwood (2012) also advises that, if a journal is able, it outsource whichever editorial processes it can.

The above discussion suggests that assuming an editorial position can negatively affect research productivity. Aguinis et al. found in their analysis of the research productivity of former management journal editors that "the amount of time, as well as pressure and stress, associated with editorship may lead to post editorship decreased productivity due to job burnout," which may be attributable in part to "too much work for the available time" $(2010,686)$. Given this possibility, the authors quote Ryan (2008) in advising that editorship be seen as "sustained volunteerism" and an "act of service," warning potential editors not to take on these roles with the assumption of post-editorship productivity or other extrinsic rewards (Aguinis et al. 2010, 686, 692). Although Aguinis et al.'s (2010) study was specific to researchers in the discipline of management, difficulty in carrying out journal activities alongside full-time academic positions was also reported by an interviewee in SSHRC's evaluation of the ASJ (SSHRC Evaluation Division 2020).

Hames (2001), Parker (2007), and Paquin (2015) all note the diversity of tasks one may undertake as part of a journal's editorial board and that these tasks will likely vary depending on the journal. Inconsistency of editorial tasks may exacerbate the existing issue of lack of training, which Aguinis et al. (2010) note is another contributing factor for burnout.

\section{Sustainability}

Aguinis et al.'s (2010) concern about the burnout potential of editorial positions is consistent with the concern of several scholars and organizations about the sustainability of journals. In the 2017 Canadian Association of Research Libraries (CARL) Canadian Scholarly Publishing Working Group report, the authors identified a weakness of the current system in that "many small independent publishers [are] reliant on a single sustaining individual; long-term sustainability is threatened" (8). Similarly, Morrison (2016), who interviewed and led focus groups with fifteen independent, scholar-led open access journals, found that "the most frequently cited need [of these journals] was ongoing, reliable funding to provide for staff resources" (87). Furthermore, according to Morrison, "providing ongoing open access requires at least modest support, especially for staffing, even for journals run almost entirely by volunteers" $(2016,84)$. Cavaleri et al. write about their experiences in launching a "shoestring" journal and express concerns that the European Journal of Comparative Economics, dependent on its "existing staff of four," could not run indefinitely $(2009,98)$. They note that part of their ability to carry on editorial work is due to their age, which provides them more time to do the work. They express concern, however, that younger scholars, "busy forming their own careers, may not be able to afford the effort" (Cavaleri et al. 2009, 100).

The ability to "afford the effort" provides the framework for how most editorial labour has traditionally been seen and rewarded. Editorial work has long been considered an act of service and is a leading reason most scholars cite for serving with editorial teams and editorial advisory boards, alongside a boost to one's reputation (Edgar and Willinsky 2010; Fyfe and Gielas 2020; Parker 2007; Schweik 2006). Nonetheless, for editorial board members who are reviewing 
papers, for example, "the actual tasks and workloads of reviewing papers are largely invisible. Few universities or business schools provide incentives or tangible recognition for the actual commitments and work that paper reviewing involves" $(2007,178)$.

Although the incentives may not be tangible, there is an argument that research and scholarly journals benefit the "knowledge commons" (Hess and Ostrom 2006). In this line of thinking, academic scholarship and research is viewed as a public good, with community benefits and contributions to the commons seen as a "voluntary" action (Hess and Ostrom 2006). The principle of voluntary labour underpinning academic journals has been a core tenant of how the knowledge commons operates: academics in a university patronage system live off their salaries rather than from direct compensation for their contribution to the knowledge commons (Eve 2017; Schweik 2006). Like any commons, however, there is the potential for social conflict. Dissatisfaction with commercial journals "free riding" on free editorial and peer review labour is part of what motivated the open access movement (Suber 2012; Macdonald and Eva 2018). It has also led to questions about whether these previously accepted forms of "free" labour, such as peer review (Brainard 2021), should now be compensated.

Though prior research has investigated editorial labour, no study to date has extensively researched the workload distribution and analyzed the job tasks within Canadian noncommercial scholarly journals. Nor has any study provided profiles of exactly how these labour practices work (e.g., which position on the journal team is responsible for which tasks? Is that work compensated? How many hours are dedicated to operating a non-commercial scholarly journal?). While, as noted above, some how-to guides exist to assist journals in setting up their operations, this paper documents the practices of existing Canadian non-commercial scholarly journals with empirical evidence.

\section{Methodology}

In order to understand the extent and depth of labour and compensation in Canadian noncommercial scholarly journals, the authors undertook a survey of journals meeting the study's inclusion criteria. First, the authors assembled a list of Canadian scholarly journals from the following sources:

- Ulrich's Periodical Directory

- CRKN list of open access journals

- Érudit

- List of journals that received the SSHRC ASJ Journals grant in 2018 or 2015

- CALJ list of current members

Starting from an initial list of 958 journals, ${ }^{2}$ the authors reviewed each journal's website to ensure it met the inclusion criteria:

- Non-commercial: Journal is not affiliated with a commercial publisher (e.g., Springer, Elsevier, Sage, etc.). Non-profits, like Cambridge University Press and the University of Toronto Press, were included.

\footnotetext{
${ }^{2}$ The original dataset of 958 journals can be retrieved from: https://doi.org/10.7939/DVN/EPSJJR.
} 
- Active: The journal published an issue in the last three years. ${ }^{3}$

- Scholarly: Definition adapted from the SSHRC ASJ criteria (2018): "peer-reviewed academic publication that disseminates the results of original scholarship." The authors recognize that this definition may have excluded journals that use alternative review models.

- Canadian: Definition adapted from the SSHRC ASJ criteria (2018): at least one third of the core editorial board is affiliated with a Canadian institution (and in their definition this includes both the editorial team and any editorial advisory body). The authors chose this definition because it recognized the labour component of journals (i.e., the editorial board). The authors considered other possible definitions (e.g., location of publisher) but utilized the SSHRC definition for both ease of use and its focus on the persons doing the work. We recognize, however, that this may have limited the journals included in the study.

The authors excluded journals falling in the following categories:

- Student journals

- Archived journals (e.g., they had published in the last three years but noted they had ceased operations)

- Conference proceedings

- Professional or trade publications

After reviewing the journal websites to verify that the journals met the inclusion criteria, the authors arrived at a list of 484 journals. Out of this list, 60 percent of the journals were fully open access $(n=292)$ and 76 percent were in the humanities and social sciences (HSS) fields $(n=$ 367) (Lange and Severson 2021). The average size of editorial teams was twenty people. Given the dominance of HSS journals in this list, ${ }^{4}$ it is not surprising that 22 percent of all journals in the dataset also currently receive funding from SSHRC's ASJ program (2018) $(n=108)$ (Lange and Severson 2021).

To disseminate the survey, the authors obtained the primary contact email from each journal's website. As the authors could not determine which member of the editorial team was responsible for the contact email, the authors included instructions to direct the email to the appropriate member of the team. The email provided instructions on the topic of the survey and let journals self-select who would be the most appropriate person to respond. We were not prescriptive in naming a particular position (e.g., editor-in-chief) because each journal would have its own unique organizational structure, positions, responsibilities, and job titles. For this reason, as well as anonymity purposes, we did not request that participants disclose their position title or name. The authors obtained ethics approval from the McGill University Research Ethics Office [REB

\footnotetext{
${ }^{3}$ This time frame was provided as a cut-off as some smaller journals publish sporadically (e.g., every one to two years). Taking this into account, the authors felt that three years was a reasonable cut-off point to determine if a journal was still active.

${ }^{4}$ Global studies on diamond OA journals (i.e., journals which charge neither author nor reader fees), found that 60 percent were in HSS disciplines (Bosman et al. 2021). Bosman et al. (2021) hypothesize that this is because HSS journals are owned by societies and universities, entities these authors argue are more likely to prefer diamond OA (in contrast to science and medicine journals owned by commercial publishers). The majority of the journals in our study use a diamond OA model; thus, the dominance of HSS in our study is in line with global numbers.
} 
\#21-01-040] and University of Alberta Research Ethics Board Office [Pro00100414_REN1] prior to sending out the survey.

Using this set of emails, the authors distributed a bilingual survey (English/French) to the contact emails of the 484 journals using the survey software LimeSurvey. Prior to distributing the survey, the authors sent a copy of the survey to four editors of Canadian non-commercial scholarly journals for feedback. Their revisions were incorporated into the final survey instrument.

An initial email inviting the journals to participate in the survey was sent on September 2, 2020 (see full survey instrument and translation in Appendices A and B respectively). A reminder email was sent on September 28 and the survey closed on October 16, 2020. The authors removed five journals for which emails could not be delivered and for which no additional contact information could be located, leaving the total potential respondents at 479 . One hundred and nineteen completed responses were received for a response rate of 25 percent. Following the completion of the survey, the authors analyzed the data using summary statistics and comment analysis.

\section{Survey Results}

\section{Participant Demographics}

The authors received a total of 119 completed responses. Of the responses, 93 were in English (80 percent) and 26 were in French ( 22 percent). By reviewing the journals' websites, the authors were able to determine that only a small subset of respondents $(n=14,12$ percent $)$ had an affiliation with a non-profit publisher (e.g., Cambridge University Press).

\section{Journal Composition}

When asked to list the total number of positions at the journal (not including peer reviewers), the average number was eleven. ${ }^{5}$ The median number was eight and the most listed number (mode) was six $(n=15)$. The median for journals associated with a non-profit publisher was 15.5 and the mode was $3(n=2)$.

In the comments for this section, twenty-two (19 percent) respondents noted that their journal functioned as a core group of members who received additional support from an infrequently consulted advisory board.

\section{Most Common Positions}

Survey respondents were asked to indicate which of the nine provided positions ${ }^{6}$ existed at their journal:

Advisory or editorial board member: Responsible for providing guidance on journal policy, direction, and best practices.

\footnotetext{
${ }^{5}$ We removed responses which included an empty value and two responses which contained errors (e.g., 1000 positions).

${ }^{6}$ We compiled the list of positions by referencing the best practice documentation in the literature review and used the most common names and definitions.
} 
Copyeditor: Responsible for improving the clarity of the writing, grammar, and spelling in manuscripts and ensuring compliance with the journal's bibliographic style.

Editorial assistant: Performs a variety of functions, including administrative tasks.

Editor-in-chief: Sets overall strategic vision and policies for the journal. Primary person in charge of leading the journal.

Layout editor: Responsible for the layout of articles. May include typesetting, conversion of manuscripts into journal template, etc.

Managing editor: Manages the day-to-day operations of the journal. Work may include scheduling, assigning editors to manuscripts, etc.

Proofreader: Responsible for reviewing the final copy (i.e., proof) of an article before it is published.

Section editor/Associate editor: Responsible for reviewing manuscripts. May also locate peer reviewers for relevant submissions

Webmaster/Journal manager: Manages the journal's website or the technical backend of the journal site.

Recognizing that journals may have different titles for similar positions, commonly held definitions of these positions were provided to assist respondents in selecting the appropriate position(s). Respondents also had the option to list any positions not included in the survey under "Other." The most commonly selected positions were editor-in-chief ( $n=105,88$ percent) and advisory/editorial board member ( $n=100,84$ percent), followed by copyeditor $(n=78,65$ percent). See Table 1 for the full list of positions and survey responses.

Table 1: Most common positions at journals as indicated by survey respondents

\begin{tabular}{|l|l|}
\hline Position (English/French) & Number of responses $(\boldsymbol{N}=\mathbf{1 1 9})$ \\
\hline $\begin{array}{l}\text { Editor-in-chief/Rédacteur en chef ou } \\
\text { rédactrice en chef }\end{array}$ & $105(88 \%)^{8}$ \\
\hline $\begin{array}{l}\text { Advisory/Editorial board member/Membre du } \\
\text { comité consultatif ou du comité de rédaction }\end{array}$ & $100(84 \%)$ \\
\hline Copyeditor/Réviseur ou réviseure linguistique & $78(65 \%)$ \\
\hline Managing editor/Directeur ou directrice de & $69(60 \%)$ \\
\hline
\end{tabular}

\footnotetext{
${ }^{7}$ Hereafter in the paper, the positions will be referred to by their English names only.

${ }^{8}$ All percentages in the paper have been rounded.
} 


\begin{tabular}{|l|l|}
\hline rédaction & \\
\hline $\begin{array}{l}\text { Layout editor/Rédacteur metteur en page ou } \\
\text { rédactrice metteuse en page }\end{array}$ & $58(49 \%)$ \\
\hline $\begin{array}{l}\text { Section editor/Associate editor/Chef de } \\
\text { rubrique/Rédacteur en chef adjoint ou } \\
\text { rédactrice en chef adjointe }\end{array}$ & $54(45 \%)$ \\
\hline $\begin{array}{l}\text { Editorial assistant/Assistant ou assistante à la } \\
\text { rédaction }\end{array}$ & $49(41 \%)$ \\
\hline $\begin{array}{l}\text { Webmaster/Journal manager - } \\
\text { Webmestre/Directeur ou directrice de la revue }\end{array}$ & $47(40 \%)$ \\
\hline Proofreader/Lecteur ou lectrice d'épreuves & $29(24 \%)$ \\
\hline Other* & $30(25 \%)$ \\
\hline
\end{tabular}

The most common "Other" positions respondents indicated were guest editor $(n=4,3$ percent), book review/reviews editor ( $n=4,3$ percent), and secretary/sécretaire/cosécretaire $(n=3,3$ percent). Other positions included variations on editor, including French editor, student editor, and deputy chief editor, as well as positions like marketer, indexing coordinator, and translator.

\section{Production Volume}

The survey included a question asking respondents to list the average number of issues produced each year. Although the authors recognize that this is not an exact measurement of a journal's output, it may provide a general proxy for a journal's volume/output.

Table 2: Number of issues produced by a journal per year according to journal team size (due to rounding, percentages may not sum to one hundred)

\begin{tabular}{|l|l|l|l|l|}
\hline & \multicolumn{3}{|c|}{ Number of issues produced per year } \\
\hline $\begin{array}{l}\text { Size of } \\
\text { journal team } \\
\text { 1-5 people }\end{array}$ & $\begin{array}{l}\text { Number of } \\
\text { responses }\end{array}$ & Average & Median & Mode \\
\hline 6-14 people & $49(30 \%)$ & 2.7 & 2 & $1(n=14)$ \\
\hline $\mathbf{1 5}+$ people & $32(28 \%)$ & $4.8^{*}$ & 2 & $2(n=26)$ \\
\hline Total & 115 & 3 & 3 & $4(n=11)$ \\
\hline
\end{tabular}

*Note: The average was affected by one journal with a particularly sizable output (i.e., an outlier). When this journal was removed from the dataset, the average number of issues per year 
for the large journals group dropped to 3.3. This number still suggests that the size of editorial staff may have an influence on the output of a journal.

\section{Hours per Position}

In the survey, respondents were provided the same list of positions and then asked to estimate how many hours of work per week were required for each position (respondents could indicate " $\mathrm{n} / \mathrm{a}$ " if the position did not exist at their journal or "don't know"). A handful of respondents ( $n=$ 5,4 percent) noted in the free-text comments the difficulty in answering this question because journal work is often clustered around the publication of an issue (rather than a set amount of hours each week). Five percent of respondents $(n=6)$ reported that several positions are a shared responsibility, once again making it difficult to numerically summarize these characteristics for individual positions. Out of the 119 completed surveys, one hundred respondents ( 84 percent) provided estimates of the number of hours worked for each position on a weekly basis (Table 3 ).

Table 3: Respondents' estimates of the number of hours/week worked for each position (due to rounding, percentages may not sum to one hundred)

\begin{tabular}{|c|c|c|c|c|c|c|c|}
\hline \multirow[t]{2}{*}{ Position } & \multicolumn{6}{|c|}{$\begin{array}{c}\text { Number of journal respondents/estimated work hours per } \\
\text { week }\end{array}$} & \multirow{2}{*}{$\begin{array}{c}\text { Total } \\
\text { number of } \\
\text { responses/ } \\
\text { position }\end{array}$} \\
\hline & $\begin{array}{l}\text { Less than } \\
1 \text { hour }\end{array}$ & $1-3$ hours & $\begin{array}{l}4-6 \\
\text { hours }\end{array}$ & $\begin{array}{l}7-10 \\
\text { hours }\end{array}$ & $\begin{array}{l}11+ \\
\text { hours }\end{array}$ & $\begin{array}{l}\text { Don't } \\
\text { know }\end{array}$ & \\
\hline $\begin{array}{l}\text { Advisory or } \\
\text { editorial board } \\
\text { member }\end{array}$ & $65(68 \%)$ & $21(22 \%)$ & $1(1 \%)$ & $1(1 \%)$ & $2(2 \%)$ & $6(6 \%)$ & 96 \\
\hline Copyeditor & $15(19 \%)$ & $31(39 \%)$ & $\begin{array}{r}9 \\
(11 \%)\end{array}$ & $\begin{array}{r}9 \\
(11 \%)\end{array}$ & $5(6 \%)$ & $\begin{array}{r}10 \\
(13 \%)\end{array}$ & 79 \\
\hline Editorial assistant & $6(12 \%)$ & $17(34 \%)$ & $\begin{array}{r}6 \\
(12 \%)\end{array}$ & $\begin{array}{r}6 \\
(12 \%)\end{array}$ & $\begin{array}{r}13 \\
(26 \%)\end{array}$ & $2(4 \%)$ & 50 \\
\hline Editor-in-chief & $9(9 \%)$ & $38(38 \%)$ & $\begin{array}{r}28 \\
(28 \%)\end{array}$ & $\begin{array}{r}10 \\
(10 \%)\end{array}$ & $\begin{array}{r}11 \\
(11 \%)\end{array}$ & $4(4 \%)$ & 100 \\
\hline Layout editor & $10(17 \%)$ & $28(47 \%)$ & $\begin{array}{r}8 \\
(14 \%)\end{array}$ & $2(3 \%)$ & $5(8 \%)$ & $\begin{array}{r}6 \\
(10 \%)\end{array}$ & 59 \\
\hline Managing editor & $8(11 \%)$ & $17(24 \%)$ & $\begin{array}{r}14 \\
(20 \%)\end{array}$ & $\begin{array}{r}12 \\
(17 \%)\end{array}$ & $\begin{array}{r}17 \\
(24 \%)\end{array}$ & $3(4 \%)$ & 71 \\
\hline Proofreader & $10(31 \%)$ & $9(28 \%)$ & $3(9 \%)$ & $2(6 \%)$ & $3(9 \%)$ & $\begin{array}{r}5 \\
(16 \%)\end{array}$ & 32 \\
\hline $\begin{array}{l}\text { Section editor/ } \\
\text { Associate editor }\end{array}$ & $11(19 \%)$ & $25(42 \%)$ & $\begin{array}{r}14 \\
(24 \%)\end{array}$ & $2(3 \%)$ & $4(7 \%)$ & $3(5 \%)$ & 59 \\
\hline $\begin{array}{l}\text { Webmaster/Journ } \\
\text { al manager }\end{array}$ & $20(40 \%)$ & $17(33 \%)$ & $\begin{array}{r}5 \\
(10 \%)\end{array}$ & $3(6 \%)$ & $2(4 \%)$ & $4(8 \%)$ & 51 \\
\hline
\end{tabular}


In looking at what percentage of each role works three hours a week or less, we can estimate which positions, on average, work the least at a journal. Below is the percentage of each position that respondents indicated worked three hours or less a week in descending order:

- Advisory or editorial board member: 90 percent $(n=86)$

- Webmaster/journal manager: 73 percent $(n=37)$

- Layout editor: 64 percent $(n=38)$

- Section editor/associate editor: 61 percent $(n=36)$

- Proofreader: 59 percent $(n=19)$

- Copyeditor: 58 percent $(n=46)$

- Editor-in-chief: 47 percent $(n=47)$

- Editorial assistant: 46 percent $(n=23)$

- Managing editor: 35 percent $(n=25)$

Conversely, if we review which positions worked seven or more hours per week at a journal, we see which positions on average work the most. We chose seven or more hours since that represents are entire day's work dedicated to the journal. Perhaps not surprisingly, this list is the inverse of the positions that worked on average the least. Below is the percentage of each position that worked seven hours or more per week in descending order:

- Managing editor: 41 percent $(n=29)$

- Editorial assistant: 38 percent $(n=19)$

- Editor-in-chief: 21 percent $(n=21)$

- Copyeditor: 18 percent $(n=14)$

- Proofreader: 16 percent $(n=5)$

- Layout editor: 12 percent $(n=7)$

- Section editor/associate editor: 10 percent $(n=6)$

- Webmaster/journal manager: 10 percent $(n=5)$

- Advisory or editorial board member: 3 percent $(n=3)$

Although these results represent aggregations, the eleven or more hours per week response option also captured several full-time salaried positions, as clarified by several respondents in the open-ended comments (e.g., thirty-five hours a week for a subscription manager).

For journals affiliated with a non-profit publisher $(n=14)$, there were more people to work on the journal, but the editors-in-chief at these journals were almost twice as likely to work four or more hours a week compared to editors-in-chief who were not affiliated with a non-profit publisher $(n=105)$. According to 79 percent of respondents affiliated with a non-profit publisher $(n=11)$, the editor-in-chief worked four or more hours a week compared to 36 percent $(n=38)$ of editors-in-chief in the remaining sample. This may be due in part to the non-profit publisher journals producing on average one more issue a year. While this seems small, that represents potentially 33 percent more content. This alone may not explain why editors-in-chief work more on average even though the editorial teams are twice the size of journals not associated with a non-profit publisher. One additional potential explanation is that non-profit publisher-affiliated journals may receive more submissions, increasing the overall workload for the editor-in-chief. 
Since these respondents represented a small percentage of the total overall, the authors are unable to make any definitive conclusions but the above suggests an area for future inquiry.

\section{Labour Division}

Survey respondents were provided with a list of standard tasks at a journal (adapted in part from Giménez-Toledo et al. 2009). Respondents were then asked to indicate which position had the primary responsibility for each task at the journal. They could also indicate if each task was not applicable or if they did not know who was responsible.

While there are some standard definitions of the roles of editorial team members (Wiley n.d.; Taylor and Francis n.d.), research by Edgar and Willinksy (2010) and Paquin (2016) suggests that there is a diversity of editorial tasks and that the positions responsible for each task are not necessarily formalized or consistent. This lack of consistency was reflected in the results of the survey shown in Table 4.

Table 4: Positions responsible for editorial tasks (due to rounding, percentages may not sum to one hundred)

\begin{tabular}{|c|c|c|c|c|c|c|c|c|c|c|}
\hline & $\begin{array}{l}\text { Recruit } \\
\text { new } \\
\text { member } \\
\text { s for the } \\
\text { journal } \\
\text { team }\end{array}$ & $\begin{array}{l}\text { Manuscrip } \\
\mathbf{t} \\
\text { solicitation }\end{array}$ & $\begin{array}{l}\text { Reviewing } \\
\text { submission } \\
\text { s before } \\
\text { peer review }\end{array}$ & $\begin{array}{l}\text { Assignmen } \\
t \text { of } \\
\text { reviewers }\end{array}$ & $\begin{array}{l}\text { Communicatio } \\
\text { n between } \\
\text { authors and } \\
\text { reviewers }\end{array}$ & $\begin{array}{l}\text { Control } \\
\text { of } \\
\text { workflo } \\
\text { w }\end{array}$ & $\begin{array}{l}\text { Copyeditin } \\
\text { g }\end{array}$ & $\begin{array}{l}\text { Layout/typesettin } \\
\mathrm{g}\end{array}$ & $\begin{array}{l}\text { Proofreadin } \\
\text { g }\end{array}$ & $\begin{array}{l}\text { Cont } \\
\text { sche } \\
\text { g }\end{array}$ \\
\hline Editor-in-chief & $53(48 \%)$ & $35(33 \%)$ & $37(32 \%)$ & $40(34 \%)$ & $24(21 \%)$ & $40(35 \%)$ & $12(10 \%)$ & $9(8 \%)$ & $18(16 \%)$ & $39(3$ \\
\hline $\begin{array}{l}\text { Section } \\
\text { editor/Associat } \\
\text { e editor }\end{array}$ & $11(10 \%)$ & $17(16 \%)$ & $22(19 \%)$ & $16(14 \%)$ & $20(18 \%)$ & $8(7 \%)$ & $8(7 \%)$ & $6(5 \%)$ & $8(7 \%)$ & $13(1$ \\
\hline $\begin{array}{l}\text { Managing } \\
\text { editor }\end{array}$ & $12(11 \%)$ & $8(8 \%)$ & $15(13 \%)$ & $17(15 \%)$ & $23(20 \%)$ & $37(32 \%)$ & $12(10 \%)$ & $15(13 \%)$ & $10(9 \%)$ & $27(2$ \\
\hline $\begin{array}{l}\text { Editorial } \\
\text { assistant }\end{array}$ & 0 & $1(1 \%)$ & $3(3 \%)$ & $6(5 \%)$ & $13(11 \%)$ & $12(11 \%)$ & $4(3 \%)$ & $6(5 \%)$ & $9(8 \%)$ & $3\left(3^{\circ}\right.$ \\
\hline Layout editor & 0 & 0 & 0 & 0 & 0 & 0 & $1(1 \%)$ & $33(29 \%)$ & $1(1 \%)$ & 0 \\
\hline Copyeditor & 0 & 0 & 0 & 0 & 0 & 0 & $47(41 \%)$ & $10(9 \%)$ & $13(11 \%)$ & 0 \\
\hline Proofreader & 0 & 0 & 0 & 0 & 0 & 0 & 0 & 0 & $12(11 \%)$ & 0 \\
\hline Webmaster & 0 & 0 & $1(1 \%)$ & 0 & 0 & 0 & 0 & $3(3 \%)$ & 0 & $1\left(1^{\circ}\right.$ \\
\hline Advisory board & 0 & 0 & $1(1 \%)$ & 0 & 0 & 0 & 0 & 0 & 0 & 0 \\
\hline Other & 0 & $1(1 \%)$ & $3(3 \%)$ & $2(2 \%)$ & $4(4 \%)$ & $5(4 \%)$ & $10(9 \%)$ & $23(20 \%)$ & 5 & $8\left(7^{0}\right.$ \\
\hline N/A & $6(5 \%)$ & $14(13 \%)$ & 0 & $2(2 \%)$ & $1(1 \%)$ & $2(2 \%)$ & $2(2 \%)$ & $1(1 \%)$ & 5 & $6\left(5^{\circ}\right.$ \\
\hline Don't know & 0 & 0 & 0 & 0 & 0 & 0 & 0 & 0 & 0 & 0 \\
\hline $\begin{array}{l}\text { Shared } \\
\text { responsibility }\end{array}$ & $29(26 \%)$ & $30(28 \%)$ & $32(28 \%)$ & $34(29 \%)$ & $29(25 \%)$ & $10(9 \%)$ & $19(17 \%)$ & $8(7 \%)$ & $33(29 \%)$ & $16(1$ \\
\hline Total responses & 111 & 106 & 114 & 117 & 114 & 114 & 115 & 114 & 114 & 113 \\
\hline
\end{tabular}


For example, the task of copyediting, although often associated with a copyeditor $(n=47,41$ percent) was also indicated as the responsibility of various other positions, including managing editor $(n=12,10$ percent), editor-in-chief $(n=12,10$ percent), and section editor $(n=8,7$ percent). This division of labour varied depending on the journal's size. For example, small journal respondents (those with between one and five people) were less likely to associate copyediting with a dedicated copyeditor $(n=8,25$ percent), while 53 percent of large journal respondents (those with fifteen or more people) indicated that copyediting was performed by a dedicated copyeditor $(n=17)$. Intuitively, this correlation makes sense as smaller teams will have fewer positions and are thus less likely to separate tasks in the division of labour across a range of positions.

In general, respondents indicated that the editor-in-chief and the managing editor were responsible for the greatest breadth of tasks. According to respondents, editors-in-chief have the primary responsibility for several tasks, including applications to have the journal indexed, assignment of reviewers, control of workflow, communication between authors and reviewers, content scheduling, manuscript solicitation, recruiting new members for the team, and reviewing submissions before sending them for peer review. Even if the editor-in-chief was not the most frequently cited person to be responsible for a certain task, they were often the second most cited person - and this was true for tasks such as updating the website and proofreading. As one respondent noted, the variety of tasks has negative consequences: "As editor-in-chief I do all the work of a managing editor (though likely should not be, as it leaves little time for strategic visioning for the journal)." Another respondent echoed the difficulty of assuming so many roles and a desire for a different structure:

The Managing Editor (myself) wears many hats - copyeditor, layout editor, typesetter, proofreader, web master [sic]/journal manager, grant writer and promotion. We are a very small, struggling, two-person "shop." We can't afford to be anything else however much we'd like to be and the inherent perils in one person acting as copy-editor, layout editor and proofreader.

According to respondents, following editor-in-chief, the managing editor is the person on the editorial team with the greatest variety of tasks for which they are solely responsible. The primary tasks of the managing editor mirror the responsibilities listed for the editor-in-chief above. In general, other than the tasks of copyediting and layout, the editor-in-chief and managing editor have a significant part in almost all tasks listed in the survey.

Respondents identified certain tasks as collaborative responsibilities rather than individual responsibilities, particularly for tasks related to peer review. For example, tasks such as assigning reviewers was a shared responsibility according to 29 percent of respondents $(n=34)$, primarily between editors and editors-in-chief $(n=13)$.

Other shared tasks include:

- Manuscript solicitation (shared responsibility in 28 percent of the responses, $n=30$ )

- Reviewing submissions before peer review (shared responsibility in 28 percent of the responses, $n=32$ ) 
- Communicating between authors and reviews (shared responsibility in 25 percent of the responses, $n=29$ )

In each of the above cases, these tasks were often a joint responsibility between section editors and another member of the team (not surprisingly, most often the editor-in-chief or managing editor).

Respondents had the opportunity to report other tasks they undertake at the journal that were not listed as specific response options in the survey. Thirty respondents reported additional tasks. In most cases these tasks were idiosyncratic (e.g., grant proposals, financial records, reports for membership, troubleshooting technical issues, meeting scheduling, strategic planning, topics for theme issues), but translation, reviewing manuscripts for plagiarism, liaising on printing/mailing, contract negotiation, administrative tasks, and sitting on society executive boards were noted by two respondents each. Three respondents also noted that the editor-in-chief takes on most remaining tasks; for example, "en tant que rédactrice en cheffe, je cumule plusieurs fonctions que j'aimerais pouvoir déléguer mais faute de moyens financiers, j'assume ces tâches" (As editorin-chief, I have several functions that I would like to be able to delegate, but due to a lack of financial means, I assume these tasks.)

\section{Compensation}

In the second half of the survey, participants were asked to indicate if journals provided monetary or non-monetary compensation and to indicate which role(s) received monetary compensation, the amount of compensation, and the source of these funds. Of the 119 respondents that completed the compensation section of the survey, 71 percent $(n=84)$ indicated that they offered compensation to at least one position in either monetary or non-monetary form. Tables 5 and 6 break down the types of compensation reported.

Table 5: Number of journals that provide compensation

\begin{tabular}{|l|l|}
\hline Types of compensation & Number of responses $(\boldsymbol{N}=\mathbf{1 1 9})$ \\
\hline Provide some compensation & $84(71 \%)$ \\
\hline Both types of compensation & $18(15 \%)$ \\
\hline Monetary compensation only & $82(69 \%)$ \\
\hline Non-monetary compensation only & $2(2 \%)$ \\
\hline
\end{tabular}

Table 6: Most common forms of non-monetary compensation

\begin{tabular}{|l|l|}
\hline Type of non-monetary compensation & Number of responses $(\boldsymbol{N}=\mathbf{8 4})$ \\
\hline Copies of the journal & $8(10 \%)$ \\
\hline
\end{tabular}




\begin{tabular}{|l|l|}
\hline Course release $^{9}$ & $5(6 \%)$ \\
\hline Conference registration and travel & $4(5 \%)$ \\
\hline Promotional items & $1(1 \%)$ \\
\hline
\end{tabular}

In the survey responses, twenty different positions were identified as receiving monetary compensation. Table 7 lists the top ten positions that were monetarily compensated and their percentages in relation to the total number of responses (as reported in Table 1). For example, twenty-four respondents indicated that copyeditors received compensation; these copyeditors represent 31 percent of the total seventy-eight copyeditors reported in the survey.

Table 7: Journal positions that receive monetary compensation according to survey respondents

\begin{tabular}{|l|l|}
\hline Position & Number of responses \\
\hline Editorial Assistant $(n=49)$ & $17(35 \%)$ \\
\hline Managing Editor $(n=69)$ & $22(32 \%)$ \\
\hline Copyeditor $(n=78)$ & $24(31 \%)$ \\
\hline Layout editor $(n=58)$ & $8(14 \%)$ \\
\hline Editor-in-chief $(n=105)$ & $12(11 \%)$ \\
\hline Section Editor/Associate Editor $(n=54)$ & $6(11 \%)$ \\
\hline Proofreader $(n=29)$ & $3(10 \%)$ \\
\hline Webmaster/Journal manager $(n=47)$ & $3(6 \%)$ \\
\hline Graphic designer & $3 *$ \\
\hline Translator & $8^{*}$ \\
\hline
\end{tabular}

In the results it was indicated that translators $(n=8)$ and graphic designers $(n=3)$ both received monetary compensation, although neither was listed as a position that respondents could select when asked about their journal's composition. Only two journals listed translators as a part of their journal composition (see Table 1).We theorize that since these positions are often "contracted" out, respondents did not always conceive of them as being a part of the editorial team. This may explain why some of these positions were indicated in the compensation section of the survey but not in the journal composition section.

When answering the questions about who was compensated, 6 percent of respondents $(n=5)$ indicated that many of these positions are "contracted" out - that is, they are not undertaken by a regular member of the editorial team but by an outside company/agency/individual. This is

\footnotetext{
${ }^{9}$ Respondents did not indicate if the journal or the institution of the editorial team member provided the course release.
} 
particularly true in the case of positions such as copyeditor, graphic designer, and translator. Three respondents ( 4 percent) also indicated they did not know how to account for being compensated when they considered the work a part of their regular academic position under the umbrella of "service." If Table 7 is compared to earlier data about hours worked, the second and third most commonly compensated positions (editorial assistant and managing editor) were also the two positions most likely to work more than seven hours per week.

Compensation ranges were provided as a part of a free-text field so were collected in a variety of formats, making it difficult to compare them. Out of the seventy journals that answered this question, some journals provided the amount as an annual salary/stipend, some as a cost per issue, while others provided an hourly wage. In addition, the amount of time that was being compensated varied greatly, with some journals providing an estimate of hours based on year, semester, or by issue. With such a range of answers it is difficult to provide any meaningful analysis. For example, the range of positions that received a stipend was anywhere between $\$ 500$ and $\$ 60,000$ a year while hourly wages ranged from $\$ 12.50$ to $\$ 50$ per hour. Three respondents (4 percent) added in their comments that they did not feel the level of compensation accurately reflected the amount of work or the level of skill or education required to do the position. As one respondent wrote, "it is a lot of work for very little compensation," and another characterized it as "zero compensation for editing a Platinum/Diamond Open Access journal, other than appreciation from colleagues and the feeling that you are fighting the good fight."

\section{Sources of Funds}

Seventy-one journals provided details on the source of the funds they use for their monetary compensation, with 45 percent $(n=32)$ indicating that they had more than one source of funds. The majority ( $n=42,59$ percent) of respondents indicated that they received funds from a sponsoring organization, whether that was through affiliation with a university department, professional association, or scholarly society, which is a notable trend. While 22 percent of respondents $(n=16)$ who answered the question mentioned that they used subscription revenue for compensation, no respondent mentioned using article processing charges (APC). Additionally, 44 percent of respondents $(n=31)$ mentioned "grants" as a funding source, with the majority of them $(n=18,25$ percent) listing SSHRC. However, thirteen (18 percent) respondents did not specify the grant source.

In order of most common, the source of funds for compensation for these seventy-one journals were:

- Sponsoring university affiliation (e.g., department, faculty) ( $n=24,34$ percent)

- Sponsoring scholarly society or association $(n=18,25$ percent)

- SSHRC ASJ grant ( $n=18,25$ percent)

- Subscription revenue ( $n=16,23$ percent)

- Other unnamed grants $(n=13,18$ percent)

- Royalties $(n=7,10$ percent $)$

- Advertising ( $n=2,3$ percent) 


\section{Comments}

At the end of the survey, respondents were given a free-text box to provide any additional comments that they had about labour in non-commercial scholarly publishing in Canada. Nearly half ( $n=55,46$ percent) of respondents provided comments. These comments were analyzed and sorted based on themes. The coding process was iterative, with the authors fully coding the entire set in a first cycle, then refining and redeveloping the codes through subsequent cycles (Saldaña 2013). To conduct the comment analysis, one author reviewed the comments initially and developed a list of themes inductively from the data. These themes and their definitions were provided to the second author, who then coded them independently. During a third round, the authors reconciled any remaining disagreements, which were minor in nature, and arrived at a final list of coded comments. Comments could receive more than one code and a list of codes and definitions is provided in Table 8. Although the authors went through several rounds of coding, we decided not to pursue formal interrater reliability analysis because the open-ended textual comments were not the primary evidence supporting this paper. We offer this analysis as anecdotal context to supplement the paper's survey data.

Table 8: List of codes and corresponding definitions for analysis of free-text comments

\begin{tabular}{|l|l|}
\hline Code & Definition \\
\hline Service & $\begin{array}{l}\text { Service as it pertains to tenure and promotion or to the scholarly } \\
\text { community }\end{array}$ \\
\hline Not recognized & $\begin{array}{l}\text { Labour not valued or recognized by community, institution, peers, } \\
\text { etc. }\end{array}$ \\
\hline Noble & Expression of sentiments as to why they undertake this work \\
\hline Lot of work & $\begin{array}{l}\text { Expression of the significant amount of labour involved, including } \\
\text { comments such as "full time job," "second job," and "lot of labour" }\end{array}$ \\
\hline Volunteer & Use of the word "volunteer" or "free labour" \\
\hline Funding & Comment related to source of funds \\
\hline OA & Comment related to open access \\
\hline Dependence & $\begin{array}{l}\text { Comment related to dependence of the journal on some variable (e.g., } \\
\text { funding, labour, etc.) }\end{array}$ \\
\hline No funding & Comment related to lack of funds \\
\hline Undercompensated & $\begin{array}{l}\text { Expression that the labour is not adequately reflected by its } \\
\text { compensation }\end{array}$ \\
\hline Prestige & $\begin{array}{l}\text { Comment related to how the journal provides prestige to } \\
\text { someone/thing (e.g., university department, etc.) }\end{array}$ \\
\hline Gratitude & Expression of gratitude for a service, person, etc. \\
\hline Concern for future & Expression of concern about the future of the journal \\
\hline Shoe string & $\begin{array}{l}\text { Comment about the small size/makeup of the journal and its } \\
\text { operations }\end{array}$ \\
\hline Fair compensation & Comment that the work is fairly compensated \\
\hline
\end{tabular}




\begin{tabular}{|l|l|}
\hline $\begin{array}{l}\text { Commercial publishers } \\
\text { (negative) }\end{array}$ & Negative comment about commercial publishers \\
\hline High-level work & Work requires many skills/skills that are high level \\
\hline Managing workload & Comment related to how the journal manages workload \\
\hline New publishing model & Comment related to new publishing models \\
\hline T\&P & Comment related to tenure and promotion \\
\hline Lack of institutional support & $\begin{array}{l}\text { Comment expressing a lack of institutional support (either monetary } \\
\text { or non-monetary) }\end{array}$ \\
\hline Institutional support & $\begin{array}{l}\text { Comment related to the existence of institutional support of some } \\
\text { kind }\end{array}$ \\
\hline Negative feeling & $\begin{array}{l}\text { Expression of some kind of negative feeling (e.g., "toxic," } \\
\text { "problematic") }\end{array}$ \\
\hline Positive feeling & Expression of some kind of positive feeling (e.g., "rewarding") \\
\hline Many hats & $\begin{array}{l}\text { Comment about the multiple jobs/roles a single person or a small set } \\
\text { of people fill at a journal }\end{array}$ \\
\hline Funding insufficient & Expression that funding is not sufficient and there should be more \\
\hline Wish/desire & $\begin{array}{l}\text { Expression of a desire for something (includes also desire to offer or } \\
\text { receive compensation) }\end{array}$ \\
\hline
\end{tabular}

In reviewing the data, the authors noted four primary themes:

\section{"It's a lot of work"}

Twenty percent of the comments $(n=11)$ noted the amount of work required to run a journal:

- "In general, a lot of free academic labour is required to make an open-access journal run well."

- "The stipend of $\$ 5,000$ a year does not reflect the amount of work ... given that it amount[s] to almost a full time job."

- "More funds are needed to provide financial compensation for these positions. It is a lot of work to create an open source journal and since it does not generate revenue, most positions are under-compensated or volunteer."

- "At times the workload is very high as these duties are on top of fulltime job requirements."

- "It is a lot of work for very little compensation and over the $10+$ years we have co-run the journal every time we try to hand the work over it stalls."

- "Editing a journal is a second full-time job. Professors/volunteers should be compensated by their universities, either monetarily, or with course relief." 


\section{Undercompensated}

Twenty percent of the comments $(n=11)$ also related to the positions not being sufficiently compensated. As noted previously, comments could be given more than one code, and these comments often appeared alongside comments about the significant nature of the work (i.e., "it's a lot of work"):

- "20 hours is not enough to run a journal; the salary is not also enough but I'm only a Phd student who did everything except peer reviewing and making editorial decisions on articles, and there was no clear budget from the university on how much they would really allot to the Journal."

- "It is a prestigious post but it is a lot of work for relatively little pay."

\section{Not recognized}

Fifteen percent of the comments $(n=8)$ also noted that despite the significant labour that goes into journal work, the work is undervalued by their institutions, colleagues, and/or funding agencies:

- "An enormous amount of uncompensated labour goes into editing a journal, and largely unrecognized in performance evaluations by our universities."

- "It is challenging to get institutions to recognize this labour for promotion, tenure, and review purposes - Does work with a journal count as service or as research? Does it count for anything?"

- "Editorial work does not receive the recognition it should from promotion committees, SSHRC, peers, etc."

- "Editorial work in scholarly publishing is taken for granted and is not compensated, generally. This continues a toxic tradition in academia of exploiting people, who typically exist on the margins of their fields, seeking full-time work."

- "Travail très important et pas toujours reconnu dans les tâches des professeurs. [Very important work and not always well-recognized in the tasks of professors]."

- "Les travaux reliés à la publication de revues savantes ne sont pas suffisamment reconnus dans les tâches professorales par les institutions universitaires. [Work related to the publication of scholarly journal is not sufficiently recognized in academic duties by academic institutions.]"

\section{Concern for the Future}

There were also expressions of "concern for the future" of the journals, including the impact of open access $(n=6 ; 11$ percent):

- "Open access will have a potential impact on labour: as subscriptions decrease, there will be less revenue to compensate labour." 
- "Our journal's funding is very uncertain, and comes in small time-limited amounts, so our capacity to compensate is constrained and variable."

- "My thought in volunteering to edit was that we all benefit from journals, and so, should all support a journal at some point in our careers. As my children are adults now, I felt able to step up. That said, the workload, plus the difficulty of recruiting volunteers, given the number of young people focused on their careers and dealing with precarious employment, make this a difficult commitment to sustain."

- "There is zero compensation for editing a Platinum/Diamond Open Access journal, other than appreciation from colleagues and the feeling that you are fighting the good fight against the shitty practices of big academic publishing. I wish/desire that more academics would wake up and realize that a critical step in the fight for open access is moving away from the big publishers towards the independents/non-profits, but it is really a losing battle despite the supposed leftist orientation of the field."

\section{Discussion}

\section{Amount of Work}

In line with the findings of the literature review, our respondents indicated that the amount of work to run a journal is significant. Other than advisory/editorial board positions, most positions at a journal require at least one to three hours of work per week, with some positions demanding significantly more. The time commitment, however, varied greatly. Although 21 percent of the editors-in-chief were estimated to work more than seven hours a week $(n=21), 47$ percent of editors-in-chief were estimated to work three hours or less $(n=47)$. It is not surprising that managing editors and editors-in-chief had both the greatest number of hours and tasks at a journal since having more tasks will logically lead to more work and hours.

Regardless of whether editors-in-chief spend one day per week or less than three hours a week on their journals, the assumptions about what editors-in-chief and managing editors do at non-commercial journals should be considered. Respondents seem to be aware of this, as one participant wrote that:

En tant que Editor-in-chief de la revue, j'effectue également la mise en page des numéros, la lecture des articles et leur révision. Je cumule donc plusieurs fonctions qui ne sont pas habituellement attribuées au Editor-in-chief. [As Editor-in-chief of the journal, I also do the layout of the issues, read the articles and edit them. So I have several duties that are not usually assigned to the Editor-in-chief.]

Recognizing the many hats that editors-in-chief and managing editors wear at noncommercial journals may be an important first step in acknowledging their labour and the potential fragility of so many tasks resting on a few positions. 


\section{Scaling Up}

The number of journal team members relates to the number of issues a journal produces. Although this linear relationship is intuitive, it suggests that "economies of scale" are not at play. If stakeholders in Canadian scholarly publishing want to see non-commercial journals flourish, we need to recognize that more output (e.g., articles) requires more people. Bo-Christer Björk (2013) notes this point as well in his analysis of business models for open access. He writes that journals which are "based on voluntary work in the spirit of Open Source projects" could not scale beyond small journals handling a "limited number of manuscripts" (Björk 2013, 9). Although the journals in this study were not exclusively open access, the sample they were pulled from included a majority of journals with no-fee open access as their business model (Lange and Severson 2021).

This finding was echoed in the Evaluation of the ASJ program (SSHRC Evaluation Division 2020), which found that funded HSS journals were significantly more likely to contract out and compensate people in production areas (compared to non-funded journals). The report hypothesized that this capacity to contract out production work was why funded journals produced more articles on average than non-funded journals (SSHRC Evaluation Division 2020).

\section{Contracting Out}

As compensation is often directed towards services such as copyediting, layout, and graphic design, we should also consider the de-professionalization of these services should revenue be lost or reduced. Martin Paul Eve's (2017) case study on XML typesetting provides a salient example of the amount of labour that technical work requires. He also cautions that "wishing this away or subsuming it under the rubric of volunteerism does not bode well for the long-term availability and archiving of scholarship" (Eve 2017,36). For library publishing programs looking to provide non-commercial publishing options, filling that gap, the question of labour may also suggest new areas of expansion. While libraries and other partners have focused on providing technical infrastructure underpinning scholarly publishing (e.g., OJS software, DOI registration, etc.), they do not typically offer the professional services (e.g., copyediting, proofreading, layout) that come with traditional publishers (Library Publishing Coalition 2020). As Lorimer notes, "the nature and costs of scholarly publishing start where the researcher and their peers leave off: with copyediting, fact- and citation-checking, layout, illustration creation, proofreading, marketing and building authoritative brands that other researchers can rely on for authority" $(2019,2)$.

\section{Compensation and Recognition}

Out of the 119 respondents that completed the compensation section of the survey, 69 percent ( $n$ $=82$ ) indicated that the journals they work for provide monetary compensation for at least one position on staff. The majority of compensated positions were non-editorial, such as graphic designer, layout editor, etc. However, one of the most commonly compensated editorial positions was managing editor - a role which was found earlier to have the greatest variety of tasks after editor-in-chief. Why managing editors are more likely to receive monetary compensation over editors-in-chief (in spite of both undertaking a variety of roles) at a journal is a surprising finding worth exploring more. Is it because editor-in-chief comes with more prestige and that acts as a form of compensation, or are editors-in-chief more likely to be full-time academics receiving "compensation" through the form of their university salary? Managing editors (alongside 
editorial assistants) were the positions most likely to work over seven hours per week and were in the top three positions to be compensated. Do journals expect these roles to work more because they are compensated? Or do people in these roles require compensation in order to be enticed to take them on given the large workload? These questions would be worthwhile to interrogate further in future studies.

The range of compensation varied too greatly to make any firm comparisons, but it was noted in the comments that the compensation level often reflected the role of the individual (as a graduate student or a postdoc) rather than the skills required for the position. What was clear from the comments was that those who answered felt that all positions were being undercompensated for both the work involved and the skill required, with several respondents noting that there was "little pay" or that pay was "non-existent." The comments conveyed respondents' frustration with the lack of recognition by their institutions, in line with the finding of Mamiseishvili, Miller, and Lee (2016) about the lack of recognition for service at higher education institutions.

Another theme worth noting is the significant role of sponsoring universities and scholarly associations. For respondents that provided compensation, the majority source of those funds, 70 percent $(n=42)$, came from sponsoring universities or scholarly associations. While there has been talk about the impact of the loss of subscription revenue on a journal's sustainability (Clavette 2018), less than half of respondents providing monetary compensation ( $n=23,38$ percent) indicated that they used either subscription or royalty revenue as the source of those funds. It would be worth looking at this closer and comparing it to the 2015 data Paquin (2016) collected to see if there have been any significant changes since SSHRC implemented open access requirements.

\section{Limitations of Study}

Although the authors endeavoured to locate a comprehensive list of journals that met their inclusion criteria, it is possible (since no definitive list exists) that journals that would have met the study's inclusion criteria were not included. Furthermore, the lack of codified language and position titles and responsibilities may have made it difficult for some respondents to list the appropriate position at their journal (despite definitions being provided in the survey to assist respondents in this task). The authors also recognize the inherent difficulty for respondents in estimating the number of hours worked by their journal's team members. We recommend that this data be seen as a general gauge of the number of hours worked, particularly in reference to other positions, and not definitive.

The authors also note the limitation in their data analysis for compensation. As we elected to give respondents a free-text box to describe their compensation structure, there is no standardized data allowing for easy cross-comparison between respondents.

Finally, the authors captured information about the number of issues a journal produced but not more precise details such as the total number of articles or length. We recognize that the number of issues is limited in terms of capturing a journal's total output and is used only as a rough proxy. 


\section{Future Research}

While this research served to document how much labour goes into non-commercial journal production as well as which positions are compensated and how, it does not delve into the motivations of editorial team members, nor does it answer the question of whether compensation should be required for such positions. At play in the current scholarly publishing system are two tensions: the rise of open access and the continuing oligopoly of commercial publishers (Larivière, Haustein, and Mongeon 2015). If scholarship is not a public good (as one could argue it is not in cases of commercial publishing), then we may expect editors and other members of the scholarly publishing community to demand monetary compensation in line with the expectations of a capitalist economy, particularly if scholars either a) no longer see their efforts being rewarded by institutions (as evidenced in some of the comments) or b) do not have stable academic employment to support their contributions. The latter may be particularly relevant as the number of tenure track positions in Canada stagnates (CAUT 2018). As noted by Eve (2017), editorial labour is already a scare resource.

Even with the altruistic motivations of open access, we still saw comments in our survey noting that for an "open-source journal . . . more funds are needed to provide financial compensation." As such, will compensation be more common in the future? Compensation is linked to funding. This was true not only in our results; according to the SSHRC Evaluation Division (2021), journals funded by SSHRC were more likely to have a higher number of paid part-time positions than non-funded journals. If compensation is to remain as it is (or decline in the event that the sources of journal funds were to dissolve), how will that affect the diversity of editorial boards? This survey did not ask respondents to indicate their position at a university or research organization, so this research does not contain data on whether the work is being carried out by tenured faculty, early career researchers, or adjuncts. Given the number of scholars who are vocal about being unable to "afford" to contribute volunteer hours to a scholarly publication, it would be worthwhile to get a better sense of who is volunteering for these positions. Editorial boards reflect the academy that they are drawn from, which has ongoing issues of equity and diversity (CAUT 2018). If funders and policy makers are committed to supporting a robust, noncommercial scholarly publishing environment, these questions need to be addressed.

Future studies may also consider investigating whether editorial structures are significantly different between commercial and non-commercial journals. While we have focused our study specifically on non-commercial journals in Canada, understanding if journals with commercial financial resources structure and compensate editorial board members in a similar (or different) manner would be intriguing. Such research could highlight if the issues related to the amount of work, recognition, and prestige are the same or are mitigated by having access to greater financial resources. It would also be worth untangling if editors associate greater prestige with working with commercial journals or journals with an impact factor. If so, are commercial journals thereby monopolizing a limited labour pool and scarce labour resource?

Given the dominance of HSS journals in this study, these results are most representative of these discipline areas rather than all non-commercial scholarly journals. As such, the results may be framed as particularly relevant to HSS journals. This research is also unable to address whether there is an ideal model for distributing the workload for scholarly journals. The survey responses demonstrate that there is significant labour involved in running a journal, but a great deal of it 
falls to one or two positions (notably the editor-in-chief and/or managing editor). Are editors burned out? Could/should work be redistributed in such a manner as to alleviate some of the workload? What would that model look like? Although redistribution of work may seem ideal, that may lead to large teams, which, as one respondent wrote, requires finding a balance "between having too big of a team yet allowing for a reasonable workload." Journals are clearly considering how best to organize these tasks, especially when fewer people may be able to volunteer to take them on. One respondent noted that "[their] workload, plus the difficulty of recruiting volunteers . . make this a difficult commitment to sustain. Hence our journal's effort to reorganize some tasks." While our research cannot definitively state if one approach is better than another, journals may at least have some evidence and guidance to compare against their own practices.

Finally, would greater recognition by universities/funding agencies, etc. encourage greater participation in and/or satisfaction with editorial positions? Many respondents remarked on how they felt the work was undervalued, with one respondent writing, "I regularly find that journal editing is treated as 'service' for the purposes of tenure and promotion while book editing is treated as 'research.' I think this is an entirely inappropriate difference and is a disincentive for people to step into the editorial role." Given the number of comments relating to the themes of workload, lack of recognition, and limited compensation, it would be timely to begin reflecting on and researching these issues.

\section{Conclusion}

Scholarly publishing continues to undergo significant shifts, and the journals that make up this ecosystem are changing and adapting within it. Although in Canada significant attention has been given to developing publishing platforms and electronic dissemination methods for these journals, less attention has been given to the labour underpinning the work. Canadian journals without large, commercial publishing houses supporting them depend on largely volunteer labour to continue their operations. This article has revealed the significant extent and scope of this labour, in particular for those in editor-in-chief or managing editor positions. It has also demonstrated that compensation is rare for these same positions and that many of those who occupy these positions suffer from a lack of recognition for this important work. In many cases, the perception of "service" to the university and contribution to the knowledge commons are why editorial team members have not traditionally been compensated. To some extent this still holds true - compensated positions tend to be related to production positions rather than editorial ones (with the exception of the managing editor). Respondents in some cases indicated that this lack of monetary and non-monetary compensation threatened the sustainability of these positions and, as such, the future of the journals that depend on such labour.

This study provides new empirical evidence on labour and compensation in Canadian noncommercial scholarly publishing. This work may assist scholars in assessing their ability and capacity to undertake editorial positions as well as help inform university promotion and tenure committees on the extent and variety of work involved in running a scholarly journal. This article may also be beneficial to library publishing programs looking to understand the types of positions involved in running a journal and assist them in advising new journals on how to structure their editorial boards and the expectation of labour and division of responsibility. While 
each journal will have its own structure dependent on its needs, editors now have evidence of how other publications operate and may find inspiration (or commiseration) in our findings.

This research has illuminated the extent and scale of the (predominantly) volunteer labour underpinning non-commercial scholarly publishing in Canada. We hope that this will lead to greater recognition for this important work and its significance to the Canadian scholarly community.

\section{Competing Interests}

The authors declare that they have no competing interests.

\section{Acknowledgements}

The authors would like to thank Katherine Hanz, Lorie Kloda, Cathy Martin, and Sébastien Breau for their assistance in reviewing the survey. We would also like to thank Alisa Rod and Benjamin Duinker for their insightful feedback on the manuscript.

\section{References}

Aguinis, Herman, Gideon P. de Bruin, Danielle Cunningham, Nicole L. Hall, Steven A. Culpepper, and Ryan K. Gottfredson. 2010. "What Does Not Kill You (Sometimes) Makes You Stronger: Productivity Fluctuations of Journal Editors." Academy of Management Learning \& Education 9 (4): 683-95. https://doi.org/10.5465/amle.9.4.zqr683.

Baruch, Yehuda. 2008. “Opening the Black Box of Editorship: Editors' Voice.” In Opening the Black Box of Editorship, edited by Yehuda Baruch, Alison M. Konrad, Herman Aguinis, and William H. Starbuck, 209-22. London: Palgrave Macmillan. https://doi.org/10.1057/9780230582590_21.

Björk, Bo-Christer. 2013. "Open Access-Are the Barriers to Change Receding?" Publications 1 (1): 5-15. https://doi.org/10.3390/publications1010005.

Björk, Bo-Christer, Cenyu Shen, and Mikael Laakso. 2016. “A Longitudinal Study of Independent Scholar-Published Open Access Journals.” PeerJ 4 (May): e1990. https://doi.org/10.7717/peerj.1990.

Bosman, Jeroen, Jan Erik Frantsvåg, Bianca Kramer, Pierre-Carl Langlais, and Vanessa Proudman. 2021. "OA Diamond Journals Study. Part 1: Findings." https://doi.org/10.5281/zenodo.4558704.

Brainard, Jeffrey. 2021. "The \$450 Question: Should Journals pay Peer Reviewers." Science, March 1, 2021. https://www.science.org/content/article/450-question-should-journalspay-peer-reviewers. Archived at: https://perma.cc/UB4T-DQMV. 
Canadian Association of Learned Journals. n.d. "Business Models." Accessed December 16, 2020. https://www.calj-acrs.ca/business-models.

Canadian Association of Research Libraries. 2017. Canadian Scholarly Publishing Working Group: Final Report. https://www.carl-abrc.ca/wpcontent/uploads/2017/07/CSPWG_final_report_EN.pdf. Archived at: https://perma.cc/JZ7B-TSSS.

Canadian Association of University Teachers (CAUT). 2018. Underrepresented \& Underpaid: Diversity \& Equity Among Canada's Post-Secondary Education Teachers. https://www.caut.ca/sites/default/files/caut equity_report_2018-04final.pdf. Archived at: https://perma.cc/NMK8-Y5QJ.

Cavaleri, Piero, Michael Keren, Giovanni B. Ramello, and Vittorio Valli. 2009. "Publishing an E-Journal on a Shoe String: Is It a Sustainable Project?” Economic Analysis and Policy 39 (1): 89-102. https://doi.org/10.1016/S0313-5926(09)50045-8.

Clark, Timothy, and Mike Wright. 2008. "Sustaining Independent Journals." In Opening the Black Box of Editorship, edited by Yehuda Baruch, Alison M. Konrad, Herman Aguinis, and William H. Starbuck, 176-87. London: Palgrave Macmillan. https://doi.org/10.1057/9780230582590_18.

Clavette, Ken. 2018. Letter to the Honourable Kirsty Duncan. January 3, 2018. Canadian Association of Learned Journals. https://www.caljacrs.ca/sites/default/files/letter to the honourable kirsty_duncan_jan_3 2018.pdf. Archived at: https://perma.cc/GT4A-6QLP.

Committee on Publications Ethics. n.d. "Journal management." Accessed December 16, 2020. https://publicationethics.org/management.

Edgar, Brian D., and John Willinsky. 2010. "A Survey of Scholarly Journals Using Open Journal Systems.” Scholarly and Research Communication 1 (2): 1-22. https://doi.org/10.22230/src.2010v1n2a24.

Eve, Martin Paul. 2017. "Open Publication, Digital Abundance, and Scarce Labour." Journal of Scholarly Publishing 49 (1): 26-40. https://doi.org/10.3138/jsp.49.1.26.

Fischer, Charles C. 2009. "Launching a New Academic Journal: Twenty Years Later." Journal of Scholarly Publishing 41 (2): 163-75. https://doi.org/10.3138/jsp.41.2.163.

Foster, Karen, and Louise Birdsell Bauer. 2018. Out of the Shadows: Experiences of Contract Academic Staff. Canadian Association of University Teachers. https://www.caut.ca/sites/default/files/cas report.pdf. Archived at: https://perma.cc/RV8X-LMPF.

Frei, Sybil, and Louise Fleming. 2016. "Survey Results_-Shaping a Collective Future.” Datahub. https://datahub.io/dataset/survey-results-shaping-a-collective-future. 
Fyfe, Aileen, and Anna Gielas. 2020. "Introduction: Editorship and the Editing of Scientific Journals, 1750-1950." In "Editorship and the Editing of Scientific Journals, 1750-1950," edited by Anna Gielas and Aileen Fyfe, special issue, Centaurus 62 (1): 5-20. https://doi.org/10.1111/1600-0498.12290.

Giménez-Toledo, Elea, Adelaida Román-Román, Pablo Perdiguero, and Irene Palencia. 2009. "The Editorial Boards of Spanish Scholarly Journals: What Are They Like? What Should They Be Like?” Journal of Scholarly Publishing 40 (3): 287-306. https://doi.org/10.3138/jsp.40.3.287.

Government of Canada, Social Sciences and Humanities Research Council. 2018. "Aid to Scholarly Journals.” https://www.sshrc-crsh.gc.ca/funding-financement/programsprogrammes/scholarly journals-revues savantes-eng.aspx. Archived at: https://perma.cc/9997-5BQE.

Hess, Charlotte, and Elinor Ostrom. 2007. Understanding Knowledge as a Commons: From Theory to Practice. Cambridge, MAass.: MIT Press.

Lange, Jessica, and Sarah Severson. 2021. "What Are the Characteristics of Canadian Independent, Scholarly Journals? Results from a Website Analysis." The Journal of Electronic Publishing 24 (1). https://doi.org/10.3998/jep.153.

Larivière, Vincent, Stefanie Haustein, and Philippe Mongeon. 2015. "The Oligopoly of Academic Publishers in the Digital Era." PloS One 10 (6):1-15. https://doi.org/10.1371/journal.pone.0127502.

Library Publishing Coalition. n.d. "Library Publishing Directory.” Accessed December 16, 2020. https://librarypublishing.org/lp-directory/.

Lorimer, Rowland. 2019. The Added Value of Canadian Journals. https://www.caljacrs.ca/sites/default/files/docs/ua-opinion-canadas-not-for-profit-journals-en.pdf. Archived at: https://perma.cc/8Z7W-NSXF.

Macdonald, Adriane, and Nicole Eva. 2018. "It's Time to Stand Up to the Academic Publishing Industry." University Affairs, February 26, 2018. https://www.universityaffairs.ca/opinion/in-my-opinion/time-stand-academic-publishingindustry/. Archived at: https://perma.cc/XN27-2GKP.

Magness, Phillip. 2016. "For-Profit Universities and the Roots of Adjunctification in US Higher Education." In Liberal Education 102 (2): 50-59. https://web.archive.org/web/20211103011435/https://www.aacu.org/liberaleducation/201 6/spring/magness

Mamiseishvili, Ketevan, Michael T. Miller, and Donghun Lee. 2016. "Beyond Teaching and Research: Faculty Perceptions of Service Roles at Research Universities.” Innovative Higher Education 41 (4): 273-85. https://doi.org/10.1007/s10755-015-9354-3. 
Maryl, Maciej, Marta Błaszczyńska, Agnieszka Szulińska, and Paweł Rams. 2020. "The Case for an Inclusive Scholarly Communication Infrastructure for Social Sciences and Humanities." [version 1; peer review: 2 approved]. F1000Research 9: 1265. https://doi.org/10.12688/f1000research.26545.1.

Morrison, Heather. 2016. "Small Scholar-Led Scholarly Journals: Can They Survive and Thrive in an Open Access Future?" Learned Publishing 29 (2): 83-88. https://doi.org/10.1002/leap.1015.

Papillon, Martin, Mélanie Bourque, Alex Marland, Brenda O’Neill, and Graham White. 2019. CSPA-SQSP Committee on the Impact of Open Access on the Canadian Journal of Political Science Preliminary Report. https://www.cpsaacsp.ca/documents/conference/2019/CPSASQSP\%20Cttee Impact\%200A\%20on\%20CJPS Preliminary\%20Report.pdf. Archived at: https://perma.cc/8HWU-UK9F.

Paquin, Émilie. 2016. Shaping a Collective Future: An Investigation into Canadian Scholarly Journals' Socio-Economic Reality and an Outlook on the Partnership Model for Open Access. Montréal, QC: University of Montréal. http://www.erudit.org/public/documents/Canadian_Journals_Socio-Economic_Study.pdf. Archived at: https://perma.cc/3ZSF-BLEJ.

Parker, Lee D. 2007. "Developing Research Journals and Qualitative Inquiry: The Role of the Editorial Board." Qualitative Research in Accounting \& Management 4 (3): 168-82. https://doi.org/10.1108/11766090710826628.

Public Knowledge Project. n.d. "Student Journal Toolkit: Journal Administration." https://docs.pkp.sfu.ca/student-toolkit/en/journal-admin. Archived at: https://perma.cc/3XXQ-XCJ7.

Ryan, Ann Marie. 2008. "How May I Help You? Editing as Service.” In Opening the Black Box of Editorship, edited by Yehuda Baruch, Alison M. Konrad, Herman Aguinis, and William H. Starbuck, 176-87. London: Palgrave Macmillan. https://doi.org/10.1057/9780230582590_3.

Saldaña, Johnny. 2013. The Coding Manual for Qualitative Researchers. London: Sage.

Schimanski, Lesley A., and Juan Pablo Alperin. 2018. "The Evaluation of Scholarship in Academic Promotion and Tenure Processes: Past, Present, and Future." [version 1; peer review: 2 approved]. F1000Research 7: 1605. https://doi.org/10.12688/f1000research.16493.1.

Schlosser, Melanie. 2018. "Building Capacity for Academy-Owned Publishing through the Library Publishing Coalition.” Library Trends 67 (2): 359-75. https://doi.org/10.1353/lib.2018.0041. 
Schweik, Charles M. 2007. "Free Open-Source Software as a Framework for Establishing Commons in Science." In Understanding Knowledge as a Commons: Theory and Practice, edited by Charlotte Hess and Elinor Ostrom, 277-310. Cambridge, MA: MIT Press.

SSHRC Evaluation Division. 2020. Evaluation of Aid to Scholarly Journals (ASJ): Final Report. https://www.sshrc-crsh.gc.ca/aboutau_sujet/publications/evaluations/2020/evaluation_report asj-rapport evaluation_aiderevues-savantes-eng.aspx\#3. Archived at: https://perma.cc/968Q-KTHZ.

Suber, Peter. 2012. "Motivation.” In Open Access, 29-48. https://doi.org/10.7551/mitpress/9286.003.0004.

Soloman, David J. 2008. Developing an Open Access Journal: A Practical Guide. https://www.uib.no/sites/w3.uib.no/files/attachments/guide to developing oa journals.p df. Archived at: https://perma.cc/483C-PBQV.

Stranack, Kevin. 2008. Starting a New Scholarly Journal in Africa. https://pkp.sfu.ca/files/AfricaNewJournal.pdf. Archived at: https://perma.cc/Z75YQVHG.

Taylor and Francis. n.d. "Managing Your Editorial Board.” Editor Resources. Accessed December 16, 2020. https://editorresources.taylorandfrancis.com/the-editorsrole/managing-editorial-boards/.

Wiley. n.d. "Editorial Resources.” Accessed March 10, 2022.

Zedeck, Sheldon. 2008. "Editing a Top Academic Journal." In Opening the Black Box of Editorship, edited by Yehuda Baruch, Alison M. Konrad, Herman Aguinis, and William H. Starbuck, 145-56. London: Palgrave Macmillan. https://doi.org/10.1057/9780230582590_15. 